\title{
ESTRATEGIAS COGNITIVAS CON ENCICLOMEDIA
}

En el contexto de las Nuevas Tecnologías en la educación en México, los profesores de educación primaria de las escuelas públicas tienen en sus salones de clase el programa Enciclomedia, que comprende básicamente de un software educativo instalado en una computadora que se proyecta sobre un pizarrón que puede ser electrónico. Esta experiencia es novedosa en la región ya que los recursos de Enciclomedia están ligados a los mismos libros de texto (en formato digital) que emplean los alumnos. Así, Enciclomedia entra con naturalidad al trabajo cotidiano de las escuelas.

Sin embargo, como se ha dicho, el recurso por sí mismo no mejorará los aprendizajes de los alumnos, ya que sigue siendo responsabilidad del profesor para mediar los nuevos recursos que se incorporan a su salón. Pero, esta intención se logra cuando la práctica docente considera diversas líneas educativas, entre ellas están las estrategias cognitivas.

Palabras clave: Enciclomedia, Estrategias cognitivas, recurso didáctico, Planeación docente.

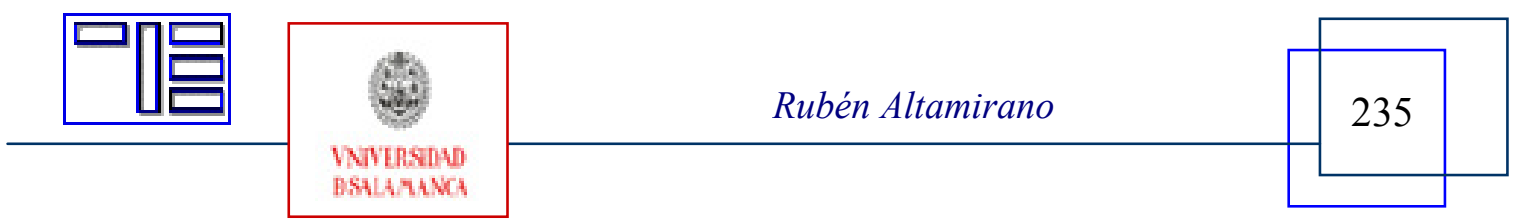


Revista Electrónica Teoría de la Educación.

Educación y Cultura en la Sociedad de la Información.

http://www.usal.es/teoriaeducacion

Vol. 7. No2. Diciembre 2006

\section{COGNITIVE STRATEGIES WITH ENCICLOMEDIA}

Within the context of new technologies applied to education, Mexican teachers at primary state schools are using a resource called Enciclomedia, which essentially is an educational software installed on a computer in the classroom, which projects digital contents on a - usually electronic - blackboard. This is a novelty in the region, given that the teaching resources available through Enciclomedia are directly linked to the digital version of the textbooks, which are used at all state schools. This is why Enciclomedia blends in very naturally as part of every day's work at Mexican schools.

However, as we know, a resource does not improve teaching just by itself, since it's the teachers' responsibility to mediate between their pupils and these new resources that are being introduced in the classroom.

Nevertheless, this can only happen if teaching practices take into consideration various educational theories, amongst which cognitive strategies.

Keywords: Enciclomedia, cognitive strategies, didactic resources, teachers' planning.

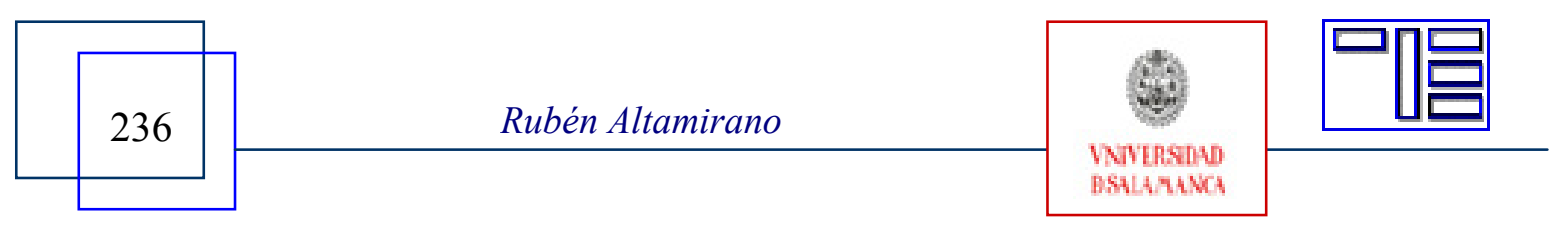




\section{STRATÉGIES COGNITIVES AVEC ENCICLOMEDIA}

Dans le contexte des nouvelles technologies et leurs applications dans le terrain de l'éducation, les instituteurs des écoles primaires publiques au Mexique utilisent une ressource qui s'appelle Enciclomedia. Essentiellement, il s'agit d'un software éducatif installé sur un ordinateur dans la salle de classe, qui projète des contenus digitaux sur un tableau noir, celui-ci normalement électronique. Le projet est une nouveauté dans la région, puisque les ressources éducatives disponibles à travers Enciclomedia sont liées directement à la version digitale des manuels qui sont employés à toutes les écoles publiques. Pour cette raison, Enciclomedia prend part, de manière très naturelle, du travail quotidien aux écoles mexicaines.

Cependant, comme nous savons très bien, una ressource ne peut pas améliorer l'enseignement toute seule, et c'est l'instituteur qui doit remplir le rôle d'intermédiaire entre ses élèves et ces nouvelles méthodes d'enseignement. Néanmoins, ceci est possible seulement si les pratiques d'enseignement considèrent une variété de théories éducatives, parmi lesquelles les stratégies cognitives.

Mots clés: Enciclomedia, stratégies cognitives, ressource.

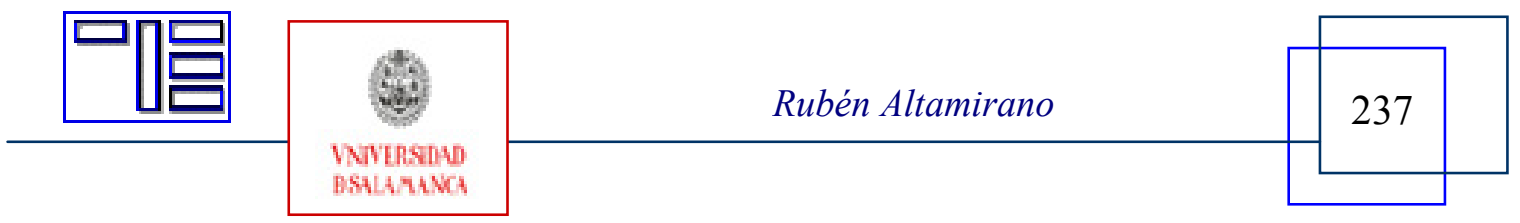


Revista Electrónica Teoría de la Educación.

Educación y Cultura en la Sociedad de la Información.

http://www.usal.es/teoriaeducacion

Vol. 7. No2. Diciembre 2006

\section{ESTRATEGIAS COGNITIVAS CON ENCICLOMEDIA}

Rubén Altamirano Contreras

rubena@ilce.edu.mx, rubenac@correo.unam.mx

Universidad Nacional Autónoma de México

“Yo creo que muchas veces confundimos 'entender' una explicación con 'aprender' el contenido explicado". Miguel ZABALZA (2000)

Ante el eminente uso de las Nuevas Tecnologías en la educación, existen todavía quienes no observan avances significativos en los resultados de aprendizaje, consideran que las Nuevas tecnologías no han logrado tener un verdadero impacto en las escuelas. No obstante, el uso de las tecnologías de la información es irreversible y cada vez con mayor presencia en la vida social. Lo que nos recuerdan que estas tecnologías no fueron creadas para alcanzar fines educativos, obligando a la escuela incorporarlas a los procesos de aprendizaje, y son los profesores responsables, en gran medida, de esa incorporación que no termina con la instalación de una máquina, de hecho se darán cuenta que apenas es el comienzo.

En México a partir del ciclo escolar 2004-2005, se ha instalado en los salones de clase de quinto y sexto grado de Educación Primaria, el programa multimedia Enciclomedia. Desde su aparición, se generó una discusión centrada en aspectos políticos, económicos, sociales e incluso culturales; en el cual el análisis pedagógico y didáctico que realmente debería ser el prioritario se omitió, pensando, quizá, que el problema era de carácter técnico- instrumental (nuevamente la escuela se convertía en una caja negra).

El uso de Enciclomedia, que seguramente representa para muchos profesores mexicanos su primer acercamiento a las denominadas Nuevas Tecnologías de la Información y la Comunicación (NTIC), supone necesariamente no sólo de una orientación práctica, sino también teórica la cual permita usar adecuadamente este recurso. Sucede que sin una formación adecuada, se corre el riesgo de que los profesores consideren que el manejo de este programa multimedia se reduce a la práctica tradicional instrumental y que bastará con apretar un botón o ver un video para que los alumnos aprendan. Pensar y actuar de esta forma reduce a la mínima expresión las aportaciones teóricas en cuanto a la

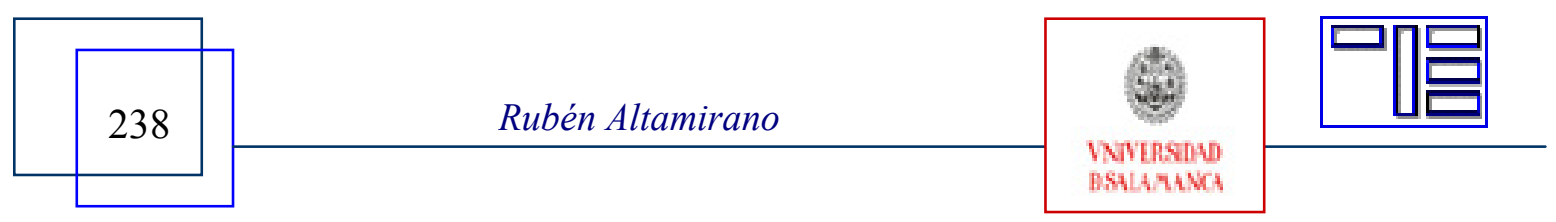


orientación de la práctica escolar con el uso de Nuevas Tecnologías. Tampoco se debe suponer en una especialización al docente en el área de la informática y la computación, sino orientarlo con base en sus diversas formas de enseñanza.

El presente documento tiene como propósito central exponer, con base en experiencias de profesores, que la verdadera utilidad de las Nuevas Tecnologías en el salón de clases vendrá de una reflexión aplicada de la didáctica-pedagógica, como la aplicación de estrategias cognitivas, por parte del profesorado para lograr que la tecnología se convierta en una innovación educativa.

\section{1.- ENCICLOMEDIA}

A pesar de los esfuerzos de algunos profesores por variar su clase, al incorporar diversos materiales didácticos; el maestro de la escuela primaria pública en México se ha caracterizado por usar el pizarrón, el gis y el libro de texto, de manera exclusiva en el desarrollo de sus clases.

Durante el 2004, el gobierno de México se fijó la meta de incorporar las NTIC a los salones de clase, al incorporar el programa Enciclomedia a las escuelas primarias públicas del país en los grados escolares de quinto y sexto[1] (niños de 10 a 12 años en promedio de edad).

Enciclomedia es un proyecto educativo que fue creado en el Instituto Latinoamericano de la Comunicación Educativa (ILCE), a través de su coordinación de Informática Educativa. La instalación del programa en las escuelas se ha realizado a través de la Secretaría de Educación Pública (SEP). Este programa fue diseñado a partir de la digitalización de los libros de texto que otorga la Secretaría gratuitamente a los alumnos de este nivel.

Un salón de clases que ya cuenta con el programa de Enciclomedia tiene instalado un video proyector (cañón), un pizarrón (electrónico o antirreflejante), una impresora, un micrófono y una computadora. El programa se encuentra en el disco duro de la máquina, por lo que no requiere estar conectado a Internet. Su contenido pedagógico se divide en dos secciones: el Sitio del Alumno y el Sitio del Maestro.

La parte usual o área de trabajo principal es el Sitio del Alumno ya que es donde trabajan cotidianamente los alumnos con su maestro en el salón de clases, porque es ahí donde están digitalizados los libros de texto del alumno de cada una de las asignaturas[2] del quinto o sexto grado.

Pero no sólo se trata de la exposición amplificada de los libros en el pizarrón (que ya de por sí es una gran ayuda) sino que la lectura de ellos ha cambiado al tener la posibilidad de acceder a otros recursos a través de ligas que están ubicadas en palabras clave de cada lección. Entre los recursos que se encuentran en Enciclomedia están: animaciones, visitas virtuales, videos, audios, artículos, mapas conceptuales, imágenes fijas, etcétera;

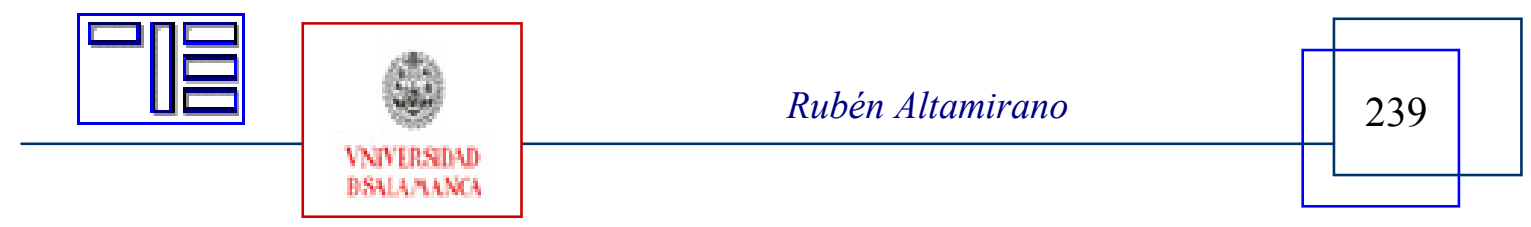


Revista Electrónica Teoría de la Educación.

Educación y Cultura en la Sociedad de la Información.

http://www.usal.es/teoriaeducacion

Vol. 7. No2. Diciembre 2006

así como de herramientas básicas como la calculadora, la regla, el grabador de voz, cronómetro, transportador y marcadores; y son estos recursos que al formar parte de una estrategia didáctica logran captar la atención de los alumnos (primer momento del proceso).

En cuanto al Sitio del Maestro, los docentes tendrán al alcance documentación oficial como el Plan y programas de estudio 1993, los Libros para el Maestro, ficheros, etcétera. Puede considerarse un área de formación y actualización permanente, por ejemplo encontrará apoyos que le permitan organizar y desarrollar adecuadamente el programa con sus alumnos a través de orientaciones de trabajo (Sugerencias didácticas) que son diseños para introducir los recursos de Enciclomedia en el trabajo cotidiano de la clase.

Se ha visto que este programa, a diferencia de otros, se incorpora de manera natural al desarrollo de las clases, ya que no es considerado como una carga extra por los maestros. Esto se debe a que Enciclomedia se ajustó a la propuesta curricular oficial a través de la temática que manejan los libros de texto; lo que le permite además impulsar nuevas estrategias de trabajo con el uso de la tecnología para alcanzar aprendizajes y no sólo adquirir informaciones que se han caracterizado por estar aisladas de los alumnos. Aunque se advierte que estos escenarios, no se alcanzarán a través de la práctica sino que se requiere de una reflexión teórica de diversas corrientes que se han desarrollado para apoyar los proceso de aprendizaje como las estrategias cognitivas.

\section{2.- ¿POR QUÉ HABLAR DE ESTRATEGIAS COGNITIVAS?}

A la fecha, todavía se piensa que la mejor manera de obtener resultados en los alumnos es memorizar o mecanizar procesos de adquisición del conocimiento (Moran, 2004); una realidad que se agudiza más con la implementación de exámenes que solicitan informaciones (acabadas). Omitiendo otras competencias que, sin duda, ante esta sociedad de la información, son igual de importantes. El conocimiento mismo no lo es, si no es de utilidad para el alumno en su entorno inmediato. Entonces seguirá siendo solamente información aislada, provocando que la enseñanza se considere una simple transmisión de contenidos (Saint-Onge, 2000)

El logro de aprendizajes significativos inicia cuando estos realmente son cercanos a los alumnos (ideas previas- conocimiento nuevo). Se ha reconocido que mientras más memorizado y aislado sea un contenido, será más fácil de olvidar. El conocimiento no se transmite, sino se construye, y es ahí donde Enciclomedia es un recurso fundamental, ya que propicia diversas situaciones para el aprendizaje basados en posturas constructivistas y cognitivas.

El empleo de estrategias cognitivas permite que el alumno pueda recordar y utilizar sin mayor problema un conocimiento en el proceso de adquisición de otro nuevo, es decir la fabricación de andamiajes en el proceso.

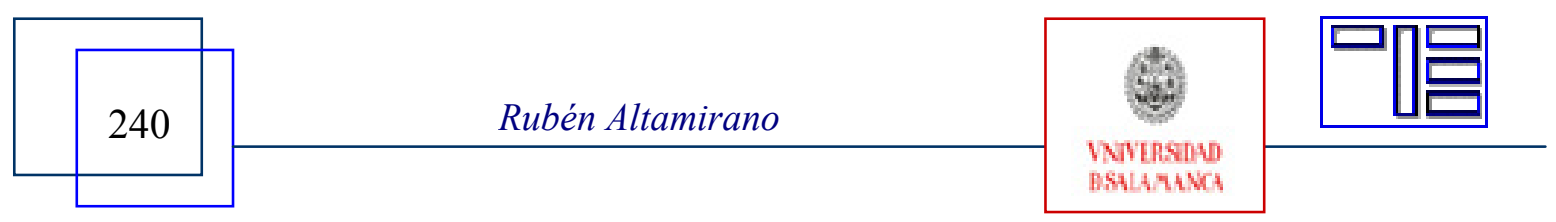


Entonces, ¿cómo lograr que los recursos que ofrece Enciclomedia efectivamente sean herramientas que desarrollen estrategias de pensamiento útiles en su vida cotidiana? Otra vez, la problemática se centra en el profesor, en su capacidad e interés para hacer un uso eficiente de este recurso. De inicio, debe recordar que cualquier recurso que utilice no es indispensable en el proceso de aprendizaje sino los usuarios. Al respecto, el constructivismo es muy claro cuando difunde la idea de que la actividad escolar debe llevarla el alumno y no el docente.

Las estrategias cognitivas junto con las NTIC permitirán al alumno aprender a resolver problemas donde Enciclomedia forme a través de sus recursos y herramientas, puentes entre las ideas previas de los alumnos y alumnas y la adquisición de nuevos conocimientos (utilizando por ejemplo, audios, videos, imágenes, mapas conceptuales).

La exposición por sí sola de una imagen no genera aprendizaje, a menos que a los alumnos les generen expectativas (con ayuda de su profesor), por ejemplo, que después de describir una imagen expresen o describan las emociones de los personajes, e inclusive "meterse" en los pensamientos del artista en caso de tratarse de una pintura. Por lo tanto el maestro no dependerá de la exposición de un video o de una animación para que el alumno de manera automática pueda comprender el contenido (suposición válida tradicionalmente cuando el maestro creía que los alumnos aprendían a través de su exposición oral); sino que los recursos del programa forman situaciones de aprendizaje y es el maestro quien deberá potenciarlas.

Las estrategias no pueden considerarse como un conjunto o listado de actividades rígidas, tampoco forman parte de un producto final; sino que la secuencia de ellas puede adaptarse a las necesidades de los alumnos en cuanto a estilos y ritmos de aprendizajes, a través de un proceso de reflexión teórico-práctico.

Ante lo mencionado, como una previa conclusión, se propone un marco de las estrategias cognitivas, en el cual es adaptable el uso de Enciclomedia:

- Considerar lo que el alumno es capaz de hacer y aprender en un momento determinado.

- Tener en cuenta los conocimientos previos

- Situar la Zona de Desarrollo Próximo

- Fomentar el aprendizaje significativo

- Priorizar la funcionalidad de lo que se aprende

- Enfatizar la actividad del alumno

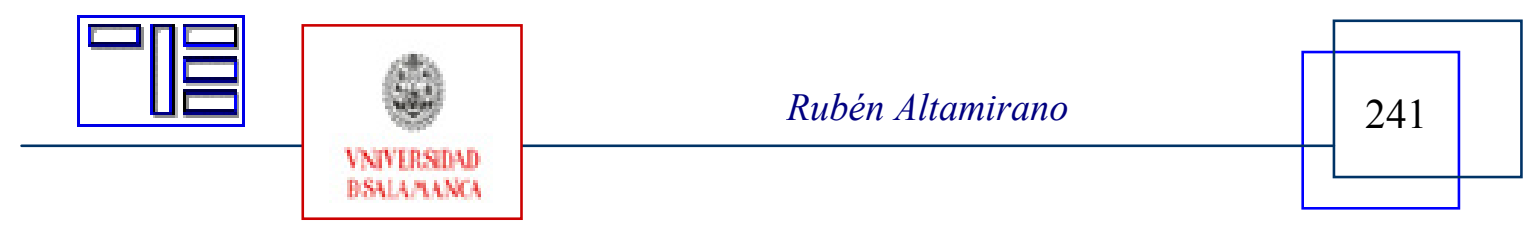


Revista Electrónica Teoría de la Educación.

Educación y Cultura en la Sociedad de la Información.

http://www.usal.es/teoriaeducacion

Vol. 7. No2. Diciembre 2006

- Desarrollar una memorización comprensiva.

\section{3.- ESTRATEGIAS COGNITIVAS CON ENCICLOMEDIA}

Se ha señalado la preocupación por almacenar información desmedida en el alumno, disminuyendo en contraparte, el proceso de reflexión y análisis, que difícilmente es considerado en el momento de anotar una calificación (reducción mínima de la evaluación); y aunque en la actualidad esto a nadie satisface, sigue siendo una práctica común en la gran mayoría de los salones de clase en nuestro país. Esta forma de enseñanza provoca en el alumno una dependencia hacia el docente en el aula, sin lograr ser autosuficiente o competente.

No obstante, el docente reconoce la importancia de usar estrategias como actividades flexibles y reflexivas e integradas en una secuencia inmersa en la estructura de la planeación de la clase.

El trabajo del docente es y será emplear los recursos y estrategias que le sean útiles para cubrir sus propósitos en el aula con sus alumnos, formular retos significativos para los alumnos. Pero esta actividad además de estar muy bien organizada, debe indicarle al alumno qué tiene que hacer. "Trabajar con Enciclomedia implica adoptar el rol de un mediador capaz de aprovechar los diferentes recursos, medios y herramientas que ofrece este sistema para propiciar mejores aprendizajes en los niños y niñas" (SEP, 2006, 3). Además mientras la estructura cognitiva sea más rica, mayor será el potencial para construir nuevos conocimientos.

En la actualidad, la informática ha sido un área explotada por la educación. Hay quienes hablan ya de aulas inteligentes, donde se tiene como objetivo principal desarrollar la inteligencia y los valores de los alumnos, además de que planifican, realizan y regulan su propio trabajo, bajo la mediación de los profesores, por medio de métodos didácticos diversificados y tareas auténticas, evaluados por alumnos y profesores, en un espacio multiuso abierto, tecnológicamente equipado y organizado según principios de la calidad total en al gestión (Segovia, 2003).

Sin embargo, un salón puede estar muy bien equipado y a la vez estar al margen del proceso de construcción de conocimientos. Es decir la computadora y el software no es garantía de aprendizajes significativos por lo que nos recuerda que el papel del docente recobra importancia, al desempeñarse como mediador entre la información, el recurso y el alumno. Sin duda los escenarios en las aulas mexicanas están cambiando, pero es el maestro, quien construya situaciones reales de aprendizaje.

En el siguiente cuadro se exponen algunas estrategias cognitivas y los recursos de Enciclomedia que pueden emplearse para cada estrategia.

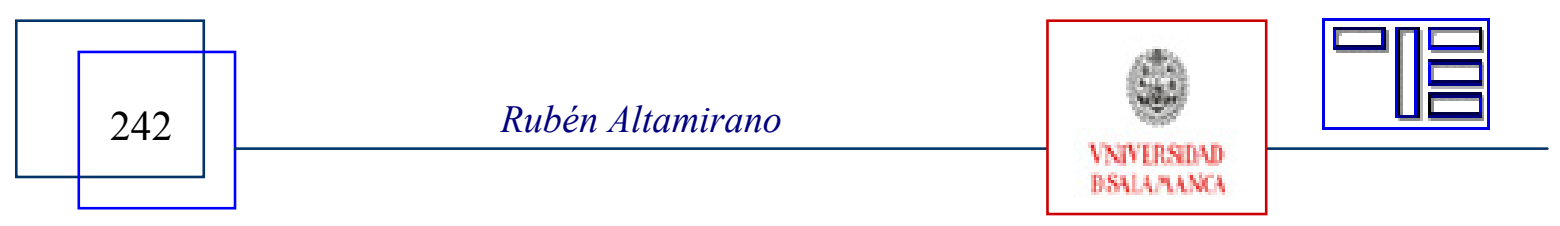


Educación y Cultura en la Sociedad de la Información.

http://www.usal.es/teoriaeducacion

Vol. 7. No2. Diciembre 2006

\begin{tabular}{|l|l|}
\hline \multicolumn{1}{|c|}{ Estrategias cognitivas } & \multicolumn{1}{c|}{ Recursos Enciclomedia } \\
\hline Explorar & $\begin{array}{l}\text { Galería de imágenes, visitas virtuales, Fonoteca, } \\
\text { Libro de texto }\end{array}$ \\
\hline Acceder al conocimiento previo & Biblioteca, Diagrama temático, Libro de texto \\
\hline Comparar & Actividades Interactivas \\
\hline Crear imágenes mentales & Mapas mentales \\
\hline Generar preguntas & Filmoteca y videos, Galería de imágenes \\
\hline Hacer inferencias & Animaciones, actividades interactivas \\
\hline Organizar gráficos & Enciclopedia Encarta \\
\hline Transferir conceptos a situaciones nuevas & Animaciones \\
\hline Ensayar & Actividades interactivas, animaciones. \\
\hline
\end{tabular}

Como se puede observar el programa permite al profesor emplear diversas estrategias docentes que logren desarrollar habilidades básicas de pensamiento en los alumnos: "Como se ha puesto de manifiesto desde la psicología cognitiva los medios nos sólo trasmiten información y hacen de mediadores entre la realidad y los sujetos, sino que al mismo tiempo por sus sistemas simbólicos desarrollan habilidades cognitivas específicas en los sujetos" (Cabero, 1997).

\section{4.- PLANEACIÓN DOCENTE}

Cuando se ha mencionado que es en las prácticas cotidianas donde se deben revisar los alcances de Enciclomedia, de ninguna manera se podrá omitir la importancia de la planeación docente, que como regla básica y elemental es que su diseño debe estar enfocado en el alumno y no ser un instrumento de carácter administrativo: “... el papel del profesor debe estar centrado en organizar el aprendizaje del estudiante más que en planificar el discurso del profesor" (Segovia, 2003, 39).

Cuando el maestro planee un tema deberá cubrir, al menos, tres criterios: aceptación (compromiso personal), bloqueo (primeros intentos errados) y exploración (explorar nuevos métodos de enfrentamiento). Una vez detectado, para asumirlo se requiere idear un plan de ataque heurístico que permita no sólo elaborar un camino, sino múltiples y todos ellos enfocados en un proceso de interacción entre maestro y sus compañeros: "...lo cognitivo no se circunscribe únicamente a lo subjetivo y personal de cada sujeto sino que abarca también el marco de las interacciones en las que el aprendizaje se produce" (Zabalza, 2000, 466).

La planeación con Enciclomedia debe contemplar que los alumnos ya poseen anclajes para recibir el nuevo material: "La interacción entre significados potencialmente nuevos e ideas pertinentes en la estructura cognitiva del estudiante da lugar a significados reales o psicológicos" (Ausubel, 2002, 27). Un recurso didáctico tradicional supone una sola visión de la realidad, sin embargo, cuando al alumno se le expone, a través de Enciclomedia, diversos medios sobre un mismo contenido permitirá tener una mejor percepción del tema:

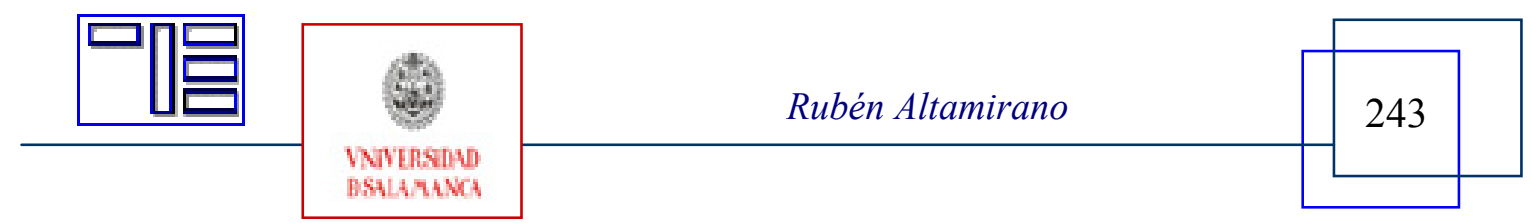


Revista Electrónica Teoría de la Educación.

Educación y Cultura en la Sociedad de la Información.

http://www.usal.es/teoriaeducacion

Vol. 7. No2. Diciembre 2006

“... el uso de recursos variados atenderá a la diversidad de estilos de aprendizaje que pueden encontrarse en el aula. La utilización de distintos medios favorecerá también el aprendizaje de los alumnos que presenten algún tipo de necesidad educativa especial. Por este motivo, deben tenerse en cuenta a la hora de establecer las diferentes aportaciones curriculares." (Mena, 1996, 90)

En la planeación de clase, la selección de un recurso, por tanto, debe ser reflexiva para involucrar todas las diferencias individuales.

MENA en su contribución sobre las nuevas tecnologías en la Educación, menciona los núcleos a considerar en una propuesta metodológica:

- El porqué enseñar (objetivos)

- Qué enseñamos y qué se aprende

- A quién (sobre estilos de aprendizaje)

- Cómo enseñar (promover procesos de interacción y las diferencias individuales)

- Propuestas metodológicas: Información, análisis, proyecto, construcción y verificación.

En sí la elaboración de un plan de clase debe ser para el maestro como un proceso de resolución de problemas que enfrenta la realidad de su salón.

\section{5.- ENCICLOMEDIA EN EL SALÓN DE CLASES}

\section{a. Sobre la información}

El programa Enciclomedia puede considerarse en un primer acercamiento, como un depósito de información, o una enciclopedia virtual, no obstante como se ha planteado, y dadas las características del programa, éste supera esta idea enciclopédica. Contrario a esto Enciclomedia es un recurso que enseña a pensar, a través de la mediación didáctica. Aún así, el docente puede ignorar esta función, nada es casual, su omisión se ha debido a exigencias externas, como los exámenes regionales y nacionales aplicados a los alumnos para evaluar al docente; se conserva la idea de que los conceptos son más importantes y determinantes en el aprendizaje de sus alumnos y no así los procesos cognitivos.

\section{b. Sobre la organización en el salón de clases}

Al igual que en experiencias donde se ha utilizado las nuevas tecnologías, el aprendizaje colaborativo es una alternativa que ha caracterizado el uso de Enciclomedia permitiendo que la construcción del conocimiento se comparta y se dialoga: "La enseñanza es un proceso de construcción cooperativa y, por lo tanto, los alcances del pensamiento reflexivo y crítico se generan en el salón de clase con los sujetos implicados" (Litwin, 2002,80 ). Cuando se ha trabajado un juego interactivo del programa se observa un am-

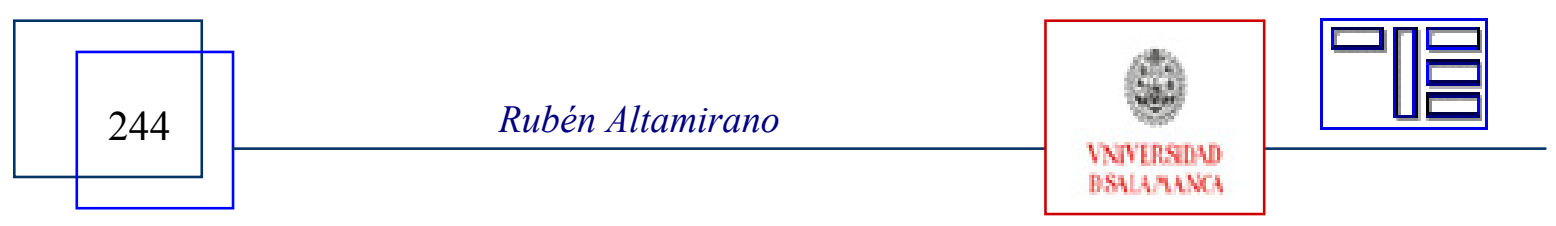


biente de cooperación entre ellos. Anterior al uso de este recurso se podía observar el temor por pasar al pizarrón y equivocarse, ahora es difícil verlo porque todos los alumnos quieren participar y exponer sus conocimientos sin miedo a equivocarse.

\section{c. Sobre el modelo de aprendizaje}

Raymond Nickerson, citado por Litwin (1997), expone cinco principios para fomentar la comprensión, que se fortalecen con los recursos de Enciclomedia bien pueden llevarse a cabo:

i. Comenzar a enseñar a partir de los conocimientos del estudiante, el profesor puede iniciar exponiendo imágenes o sonidos.

ii. Promover el pensamiento activo, cuando participa en actividades interactivas $\mathrm{y}$ animaciones

iii. Usar representaciones apropiadas, cuando realiza actividades interactivas

iv. utilizar simulaciones, cuando observa animaciones y actividades interactivas.

v. Proveer de entornos de apoyo, Cuando participa en visitas virtuales.

No se busca un recurso que solucione los problemas del profesor, sino que permita que tome conciencia de sus decisiones como sujeto que enseña. Al docente no debe interesarle el video mismo, sino lo que está siendo con él y cómo lo está aplicando. También la falta de aprendizaje se debe al poco interés de los alumnos al contenido, basta ver cómo los niños adoptan posturas abiertas para conocer más en una clase de historia, por ejemplo.

\section{d. Sobre la capacitación y papel docente}

¿Cuál es el rumbo de la capacitación? Quizá muchos piensen que debe estar dirigida hacia el uso de las Tecnologías, probablemente, aunque gran parte deberá estar relacionada con la práctica docente y esta nos llevará a terrenos alejados del contexto informático. "El maestro debe saber enseñar. Pero hay que preguntarnos: ¿qué es enseñar hoy? ¿Qué implica enseñar?” (Bedoya, 2002, 91).

Es decir la capacitación debe enfocarse al reconocimiento del programa pero además y en mayor medida cómo utilizarlo. Y será entonces un retorno a viejas teorías educativas que casualmente son olvidadas en la práctica. Por eso, enseñar, en sí, debe propiciar autonomía en la construcción del conocimiento, fin último de las estrategias cognitivas y metacognitivas (independiente de un examen, notas de clase o tareas), debe motivar a la reflexión crítica.

La capacitación deberá convertirse en una formación docente permanente que esté encaminada a insistir en la actitud del docente por mejorar sus clases, asumir en otras palabras, el papel de investigador de su práctica. En la Declaración de Dakar (2000) se señala oportunamente que "No se conseguirá un reforma educativa con resultados posi-

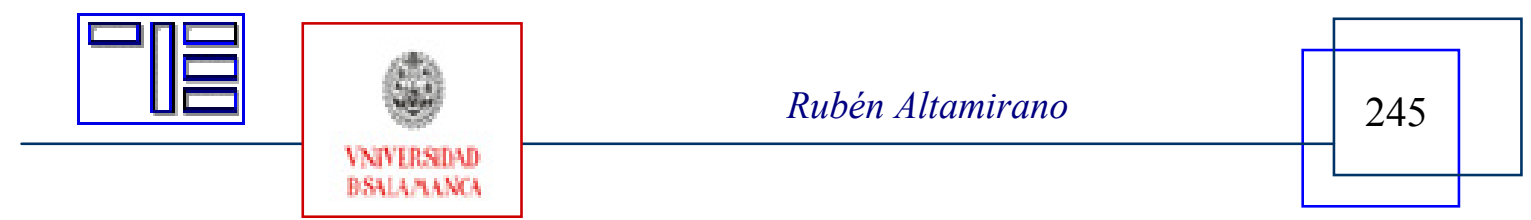


Revista Electrónica Teoría de la Educación.

Educación y Cultura en la Sociedad de la Información.

http://www.usal.es/teoriaeducacion

Vol. 7. No2. Diciembre 2006

tivos si los docentes no participan de forma activa". Enciclomedia provoca repensar la función de la escuela primaria en México, porque su uso le permite al maestro incluir sus procesos de pensamiento, sus rutinas, sus creencias a su forma de enseñar.

\section{6.- COMENTARIOS FINALES}

Contrario a lo que se diga sobre el uso de las nuevas tecnologías sea meramente práctico o técnico, insistimos en la idea que será pues necesario retomar posturas teóricas que nos permitan valorar la forma de enseñar empleando diversos recursos. Por tanto, el maestro está obligado a valorar y conocer una cultura tecnológica, se lo exige la sociedad, que se caracteriza por el homo videns y que además “... es necesaria también para pensar las relaciones entre la evolución de los instrumentos (informático e hipermedia), las competencias intelectuales y la relación con el saber que la escuela pretende formar." (Perrenoud, 2004,119) Pero además debe estar enriquecido de teorías que le ayuden a comprender su práctica misma y le permita adquirir aprendizajes.

Asimismo, el programa Enciclomedia puede favorecer el aprendizaje del alumno pero su alcance estará determinado por las prácticas que realice el docente. Por eso su mayor utilidad debe encontrarse en permitirle al alumno a acceder al conocimiento implementando estrategias cognitivas, que lo guíen a construir habilidades de pensamiento, sin creer que no se pueda lograr de otra manera, las nuevas tecnologías de ninguna manera serán la panacea de los problemas educativos, pero sí puede potenciar situaciones de aprendizaje que no se limiten a la adquisición (acumulación) del conocimiento, sino que sepa dónde y cuándo lo utilizará. Pero esto sucederá sólo sí el profesor cree necesario replantear su quehacer frente a las nuevas aportaciones científicas y tecnológicas. Las características recientes del mundo social y de los avances tecnológicos exigen un desarrollo permanente de los docentes.

El uso de las nuevas tecnologías con un enfoque hacia la elaboración de estrategias cognitivas forman parte de una alternativa que al paso del tiempo generará cambios en los aprendizajes; sin embargo, la evaluación sobre el impacto del uso de este recurso no podrá reflejarse a través de una prueba estandarizada ya que omitiría cambios que se están gestando como el cambio de actitud para aprender o la capacidad de trabajar en equipo, por tanto, coincido con Angela McFarlane (2001) en la elaboración de una evaluación global que contextualice el proceso de enseñanza aprendizaje (otros lo llaman aprendizaje situacional) para obtener un verdadero balance de las TICS sobre los logros educativos

\section{7.- BIBLIOGRAFÍA}

ALTAMIRANO, R. (2006) "Enciclomedia y la interacción en el aprendizaje escolar" en Revista Educación 2001, México, núm. 130, marzo, pp. 49-52.

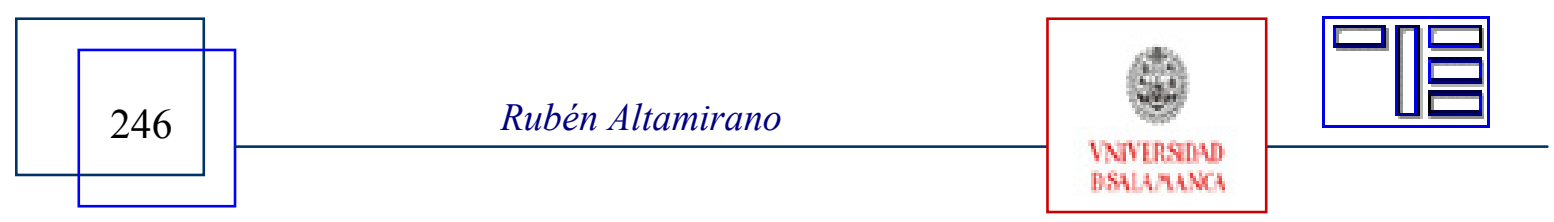


(2006) "Enciclomedia. Nuevas situaciones para aprender y enseñar" en Revista Educar, México, no. 38, julio-septiembre, Secretaría de Educación de Jalisco, pp. 92-97.

(2005) "Enciclomedia y su intervención mediática. Más allá del recurso didáctico" en Revista Entre maestr@s, núm. 14, UPN, México. Otoño, pp. 21-29.

AUSUBEL, D. (2002) Adquisición y retención del conocimiento, España, Paidós.

BAUTISTA, A. (1994) Las nuevas tecnologías en la capacitación docente, Madrid, Visor.

BEDOYA, J.(2002) Pedagogía ¿enseñar a pensar? Reflexión filosófica sobre el proceso de enseñar. Colombia, Ecoe ediciones.

BLYTHE, T. y otros (2004) La enseñanza para la comprensión. Guía para el docente, $2^{\mathrm{a}}$ reimp., Buenos Aires

COLL, César (2006) "Vigencia del debate curricular. Aprendizajes básicos, competencias y estándares" Ponencia presentada en la Segunda reunión del Comité Intergubernamental del Proyecto Regional de Educación para América Latina y el Caribe. Santiago, Chile, UNESCO, 11 al 13 de mayo.

CABERO, J. (1996) "Nuevas tecnologías, comunicación y educación” Edutec. Revista Electrónica de tecnología educativa, no. 1

CUBO, S. (2003) "Perspectiva pedagógica de los multimedia" en Revista española de pedagogía, no. 225, mayo-agosto.

ELIZONDO, et. al. (2006) "Enciclomedia. Un programa a debate" en Revista Mexicana de Investigación Educativa, Enero-Marzo, Vol. 11, núm. 28. 209-224pp.

LITWIN, E. (1997) Las configuraciones didácticas, México, Paidós.

McFARLANE, A. (2001) El aprendizaje y las tecnologías de la información, México, SEP/Alfaguara.

MENA, B. (coord.) (1996) Didáctica y nuevas tecnologías en educación, España, ed. Escuela Española.

MORÁN, P. (2004) "La docencia como recreación y construcción del conocimiento. Sentido pedagógico de la investigación en el aula" en Revista Perfiles educativos, núm. 105-106, México, CESU-UNAM. 41-72pp.

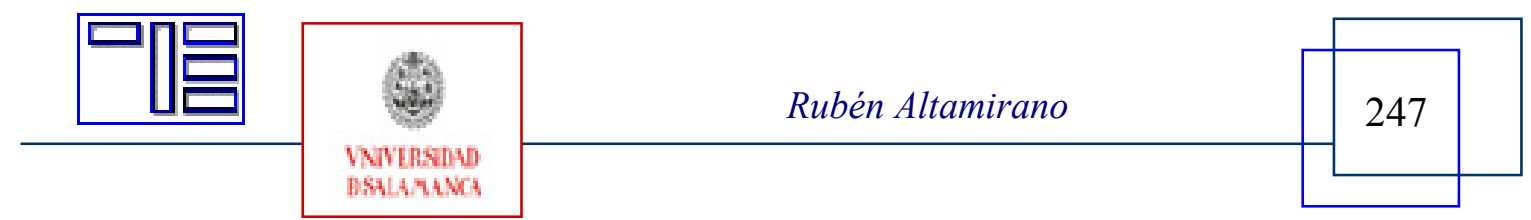


Revista Electrónica Teoría de la Educación.

Educación y Cultura en la Sociedad de la Información.

http://www.usal.es/teoriaeducacion

Vol. 7. No2. Diciembre 2006

PERRENOUD, P. (2004) Diez nuevas competencias para enseñar, México, SEP/Graó.

PISCITELLI, A. (2006) "Nativos e inmigrantes digitales. ¿Brecha generacional, brecha cognitiva o las dos juntas y más aún?", Revista Mexicana de Investigación Educativa, Enero-Marzo, Vol. 11, núm. 28. 179-185pp.

SAINT-ONGE, M. (2000) Yo explico pero ellos... ¿aprenden?, México, SEP/FCE/Mensajero.

SEGOVIA, F. (2003) El aula inteligente. Nuevas perspectivas, España, Espasa.

SEP (2006) El sitio del maestro y la tarea de enseñar. México, SEP.

UNESCO, (2000) Declaración de Dakar. Foro mundial sobre la educación, Abril. Fuente: http://www.unesco.org.uy/educacion/docs/summary_spa.pdf Consulta: marzo, 2006.

VIDALES, I. (2006), El programa Enciclomedia en las escuelas primarias de Nuevo León, México, Santillana.

ZABALZA, Miguel (2000) "Estrategias didácticas orientadas al aprendizaje" en Revista española de pedagogía, no. 217, septiembre-diciembre. 459-490pp.

\section{Notas}

[1] Alumnos con un intervalo de edad entre 10 y 12 años.

[2] Los libros digitalizados pertenecen a las asignaturas de Español, Matemáticas, Ciencias Naturales e Historia, así como los libros: Atlas de México, Atlas Universal y Conoce nuestra Constitución (que abordan temáticas de Geografía y Educación Cívica)

\section{Para citar este artículo puede utilizar la siguiente referencia:}

ALTAMIRANO CONTRERAS, Rubén (2006): Estrategias cognitivas con Enciclomedia. En GARCÍA CARRASCO, Joaquín (Coord.) Estudio de los comportamientos emocionales en la red [monográfico en línea]. Revista Electrónica Teoría de la Educación: Educación y Cultura en la Sociedad de la Información. Vol. 7, n 2 . Universidad de Salamanca. [Fecha de consulta: dd/mm/aaaa].

$<\mathrm{http}: / /$ www.usal.es/ teoriaeducacion/rev_numero_07_02/n7_02_ruben_altamirano.pdf > ISSN 1138-9737

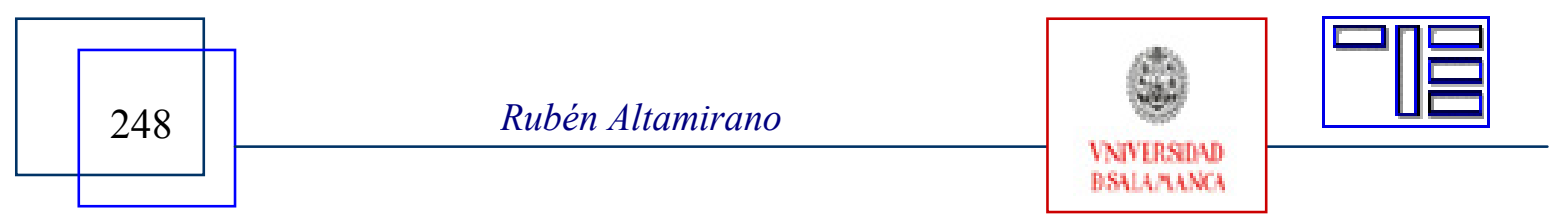

